\title{
From the Journal archives: A harbinger of modern anesthesia
}

\author{
Edmond I. Eger II, MD
}

Received: 31 May 2013/Accepted: 11 October 2013/Published online: 19 November 2013

(c) Canadian Anesthesiologists' Society 2013

\section{Editors' Note: Classics Revisited \\ Key Articles from the Canadian Journal of \\ Anesthesia Archives: 1954-2013}

As part of the Journal's $60^{\text {th }}$ anniversary Diamond Jubilee Celebration, a number of seminal articles from the Journal archives are highlighted in the Journal's $61^{\text {st }}$ printed volume and online at: www.springer.com/12630. The following article was selected on the basis of its novelty at the time of publication, its scientific merit in pushing a still relatively young field of research forward, and its overall importance to clinical practice: Oyama $T$, Shibata S, Matusmoto F, Takiguchi M, Kudo T. Effects of halothane anaesthesia and surgery on adrenocortical function in man (Can Anaesth Soc J 1968; 15: 258-66). Dr. Edmond I. Eger II provides expert commentary on this paper, the first of several related studies by this prolific group that examined the hormonal responses to anesthesia and surgery.

Hilary P. Grocott MD, Editor-in-Chief

Donald R. Miller MD, Former Editor-in-Chief

\section{Background}

From the discovery of anesthesia in 1846 until the 1960s, anesthetic investigations focused largely on the management

\section{E. I. Eger II, MD ( $\square)$}

Department of Anesthesia and Perioperative Care, University

of California, San Francisco, 513 Parnassus, Box 0464,

San Francisco, CA 94143-0464, USA

e-mail: egere@anesthesia.ucsf.edu of clinical problems. The 1960s saw increasing attention to the dose-related effects of anesthesia on the vital processes of the body. Investigators interested in anesthesia developed tools for defining anesthetic kinetics (what the body does to anesthetics) $^{1}$ and comparative pharmacodynamic effects (the relative effects of what anesthetics do to the body). In 1968, the Canadian Journal of Anaesthesia published an article by Tsutomu Oyama (1923-2008) et al. entitled "Effects of halothane anaesthesia and surgery on adrenocortical function in man", ${ }^{2}$ which is an exemplar presaging the expansion of pharmacodynamic studies. Before the 1960s, relatively little was known of the effects of anesthetics on the body, in this case, specifically the release of free corticosteroids, such as, 17hydroxycorticosteroids (17-OHCS), especially in humans. Oyama opened a new window.

\section{Study summary}

Oyama et al. studied three groups each with 10-11 patients. Following the custom of the day, each patient received pentobarbital, meperidine, and atropine premedication. Group 1 received thiopental to induce anesthesia and succinylcholine to facilitate tracheal intubation. Halothane plus nitrous oxide induced anesthesia in Group 2 and apparently supplied relaxation sufficient to permit tracheal intubation (i.e., paralysis with succinylcholine was not used). For both Groups 1 and 2, anesthesia continued with $50 \%$ nitrous oxide and $0.5-1.5 \%$ halothane as indicated clinically. Similarly, intermittent doses of succinylcholine $20 \mathrm{mg}$ supplied relaxation during surgery.

Free corticosteroid concentrations in plasma were ascertained in blood taken "1) the day before surgery at 3-5 p.m., 2) immediately before induction of anesthesia, 3) 15 min after induction of anesthesia (first group), 4) 
$30 \mathrm{~min}$ after induction of anesthesia (second group), 5) immediately prior to the commencement of surgery (second group), 6) immediately after the start of surgery (first group), 7) one to two hours after start of surgery, 8) in the recovery room".

In Group 3, free 17-OHCS concentrations in plasma were ascertained at 8:15-8:45 a.m. on one day and at the same time on the next day after premedication. These control patients were not scheduled for surgery. The data from Group 3 indicated that premedication decreased free corticosteroids, with plasma values decreasing from a mean (SD) of 18.2 (1.6) $\mathrm{mg} \cdot 100 \mathrm{~mL}$ to 14.0 (1.2) $\mu \mathrm{g} \cdot 100 \mathrm{~mL}$. Thus, the patients in Groups 1 and 2 had initial values for corticosteroids that were lower than the norm (Fig. 1). Corticosteroids did not increase with induction of anesthesia with thiopental; however, they did increase with halothane and nitrous oxide (Fig. 1). During the stimulation caused by surgery, all subsequent values for both groups exceeded control values.

\section{Implications}

Oyama undertook his study "to investigate whether or not preanesthetic medication and halothane anaesthesia affect adrenal cortical function in man", and concluded that premedication decreased corticosteroids, and in the absence of an inducing dose of thiopental, induction of anesthesia with halothane and nitrous oxide increased corticosteroids. The stimulation of surgery caused a further and larger increase in corticosteroids. Many prior studies of

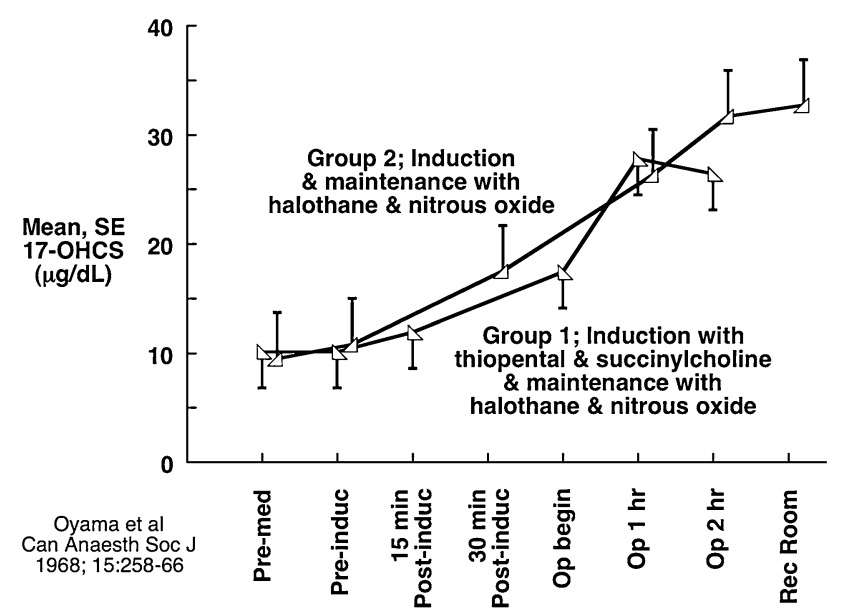

Fig. 1 Over the course of anesthesia with halothane and nitrous oxide, Oyama et al. $^{2}$ found that plasma 17-hydroxycorticosteroids (17-OHCS) in patients increased with stimulation by induction of anesthesia with inhaled anesthetics but not with thiopental. They also found that ongoing surgery caused a greater increase in corticosteroids, indicating that anesthesia did not block the perception of or response to noxious stimulation the anesthetic effects on corticosteroids in humans suffered from the confounding effects of surgery. Part of Oyama's considerable contribution was to seize on the period before surgery to isolate the effect of the anesthetic itself, but the time available to accomplish this may have been insufficient (see below).

From 1968 onward, Oyama took the lead in supplying information on the effects of anesthesia on endocrine function, a prolific output over five years (Fig. 2). Oyama's study opened the door to several further investigations, investigations that sought to answer questions such as: Were there differences among anesthetics regarding their effects on corticosteroids, and were the effects of anesthetics influenced by anesthetic dose or duration of anesthesia? Oyama repeated his studies substituting methoxyflurane, ${ }^{3}$ ether, ${ }^{4}$ enflurane, ${ }^{5}$ isoflurane, ${ }^{6}$ and sevoflurane $^{7}$ for halothane, usually finding similar results. For example, as with his studies with halothane and nitrous oxide, he found that ether anesthesia increased corticosteroids in humans in the half hour after induction of anesthesia, with surgery augmenting the increase. ${ }^{4}$ Oyama associated these increases with a rise in adrenocorticotropic hormone (ACTH). In general, he found that diverse anesthetics alone had little effect on or decreased plasma cortisol values, but tracheal intubation and surgery, despite the presence of anesthetic drugs, prompted an increase - indicating that anesthesia with conventional inhaled and injected agents did not completely block the perception of and response to noxious stimulation. Surprisingly (at least to me), administration of larger doses of meperidine [336 (131)

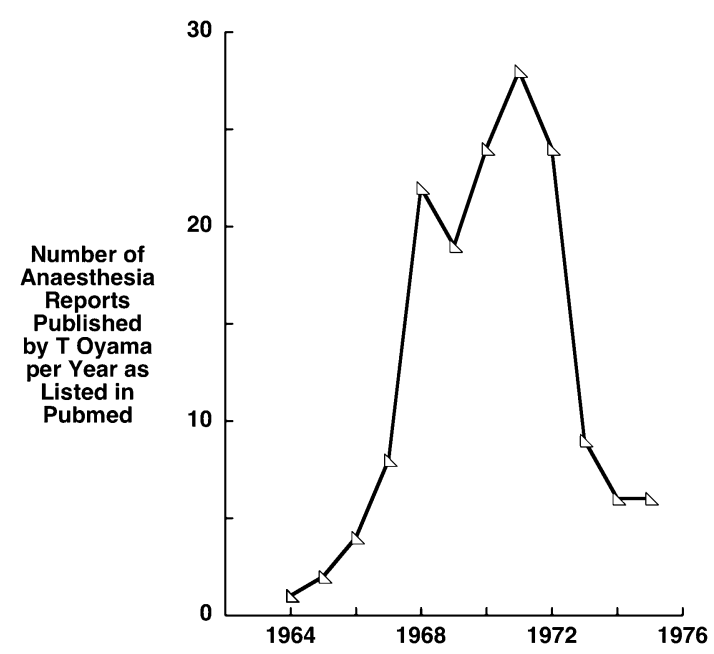

Fig. 2 Over a relatively brief period of time (1968-1972), Oyama et al. produced a body of knowledge in dozens of reports that defined the major effects of anesthetics on plasma hormonal levels and responses in the perioperative period 
$\mathrm{mg}$ ] did not prevent the increase in corticosteroids associated with surgery, ${ }^{8}$ nor did anesthesia with ketamine. ${ }^{9}$ Corticosteroids levels changed little or not at all during surgery under spinal anesthesia. ${ }^{10}$

As mentioned above, Oyama made use of the period before surgery to define the effects of anesthesia in the absence of surgery; however, he often could not exclude the effect of the excitement of induction or the stimulation provided by placement of a tracheal tube. Moreover, Oyama's approach could not test the impact of the effect of longer durations of anesthesia without the stimulation provided by surgery. von Werder et al. supplied this additional information, ${ }^{11}$ supporting and enlarging on Oyama's observations. In this case, von Werder avoided the limitations imposed by the use of patients and studied volunteers. Like Oyama, von Werder anesthetized some of his subjects with nitrous oxide-halothane and intubated the trachea, finding that the excitement and stimulation associated with induction with nitrous oxide increased corticosteroids (in this study, 11-hydroxycorticosteroids [11-OHCS]) (Fig. 3). Plasma 11-OHCS values increased from $11.7(2.3) \mu \mathrm{g} \cdot \mathrm{dL}^{-1}$ (control) to the values seen initially in Fig. 3 (i.e., values exceeding $20 \mu \mathrm{g} \cdot \mathrm{dL}^{-1}$ ). Unlike Oyama's patients, however, von Werder's volunteers were

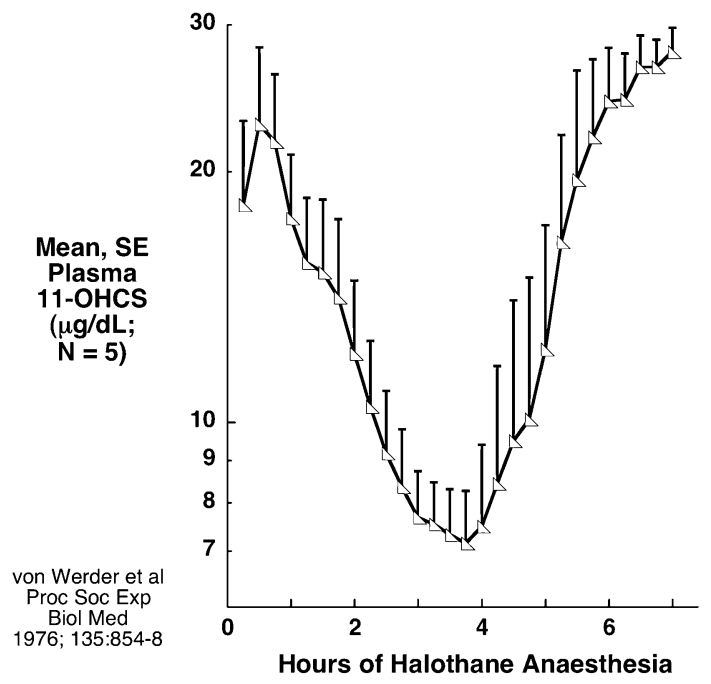

Fig. 3 von Werder et al. similarly found in volunteers what Oyama et al. found in patients (Fig. 1), i.e., the excitation associated with induction of anesthesia with nitrous oxide plus halothane increased plasma corticosteroids (data for the first $45 \mathrm{~min}$ ). Prior to anesthesia, the mean (SD) value for 11-hydroxycorticosteroids (11-OHCS) was 11.7 (2.3) $\mu \mathrm{g} \cdot \mathrm{dL}^{-1}$ ( $n=5$; data not shown on graph), increasing to more than $20 \mu \mathrm{g} \cdot \mathrm{dL}^{-1}$ immediately following induction of anesthesia and tracheal intubation. Subsequently, the results by Oyama and von Werder diverged, almost certainly because of surgery performed on Oyama's subjects but not on von Werder's volunteers. In the absence of surgery, von Werder found that plasma corticosteroids decreased over three hours to Addisonian values not subsequently stimulated with surgery, although they were tested later in the study for their response to increasing concentrations of halothane. In the absence of stimulation, corticosteroid concentrations progressively decreased over the ensuing three to four hours reaching Addisonian values. The nadir for the corticosteroid concentrations arrived just prior to four hours of anesthesia.

Then a strange thing happened. Corticosteroids increased fourfold over the next two hours despite an absence of obvious stimulation. Peaks in growth hormone also occurred, ${ }^{12}$ but a temporal connection to the corticosteroid peaks was inconsistent.

Oyama expanded his investigations to measure the effects of injected anesthetics and anesthetic adjuvants, such as muscle relaxants ${ }^{13}$ and hypothermia. ${ }^{14}$ He explored the actions of both inhaled and injected anesthetics on other hormone levels, for example, concentrations of thyroid hormone, ${ }^{15}$ testosterone, ${ }^{16}$ human growth hormone and insulin levels, ${ }^{17}$ and plasma antidiuretic hormone. ${ }^{18}$ His collective work produced a body of knowledge, including reviews ${ }^{19,20}$ and a book, Anesthetic Management of Endocrine Disease, ${ }^{21}$ that provided a comprehensive view of the importance of anesthesia and anesthetic agents to endocrine changes and to the practice of anesthesia. Until and beyond his retirement in 1989, Oyama continued to contribute to our understanding of anesthetic influences on hormone function, but the intensity of his output never exceeded that of the five years beginning in 1968, the year his article, "Effects of halothane anaesthesia and surgery on adrenocortical function in man", was published in the Journal.

Acknowledgement The author values the help given by Kazuyoshi Hirota MD PhD FRCA, Professor and Chairman, Department of Anesthesiology, Hirosaki University Graduate School of Medicine.

Funding sources None.

Conflicts of interest None declared.

\section{References}

1. Price HL. A dynamic concept of the distribution of thiopental in the human body. Anesthesiology 1960; 21: 40-5.

2. Oyama T, Shibata S, Matusmoto F, Takiguchi M, Kudo T. Effects of halothane anaesthesia and surgery on adrenocortical function in man. Can Anaesth Soc J 1968; 15: 258-66.

3. Oyama T, Shibata S, Matsumoto F, et al. Adrenocortical function related to methoxyflurane anaesthesia and surgery in man. Can Anaesth Soc J 1968; 15: 362-8.

4. Oyama T, Saito T, Isomatsu T, Samejima N, Uemura T, Arimura $A$. Plasma levels of ACTH and cortisol in man during diethyl ether anesthesia and surgery. Anesthesiology 1968; 29: 559-64.

5. Oyama $T$, Taniguchi $K$, Ishihara $H$, et al. Effects of enflurane anaesthesia and surgery on endocrine function in man. $\mathrm{Br} \mathrm{J}$ Anaesth 1979; 51: 141-8. 
6. Oyama T, Latto P, Holaday DA. Effect of isoflurane anaesthesia and surgery on carbohydrate metabolism and plasma cortisol levels in man. Can Anaesth Soc J 1975; 22: 696-702.

7. Oyama T, Murakawa T, Matsuki A. Endocrine evaluation of sevoflurane, a new inhalation anesthetic agent. Acta Anaesthesiol Belg 1989; 40: 269-74.

8. Oyama T, Takiguchi M, Takazawa T, Kimura K. Effect of meperidine on adrenocortical function in man. Can Anaesth Soc $\mathbf{J}$ 1969; 16: 282-91.

9. Oyama T, Matsumoto F, Kudo T. Effects of ketamine on adrenocortical function in man. Anesth Analg 1970; 49: 697-700.

10. Oyama T, Matsuki A. Plasma levels of cortisol in man during spinal anaesthesia and surgery. Can Anaesth Soc J 1970; 17: 23441.

11. von Werder K, Stevens WC, Cromwell TH, Eger EI 2nd, Hane S, Forsham $\mathrm{PH}$. Adrenal function during long-term anesthesia in man. Proc Soc Exp Biol Med 1970; 135: 854-8.

12. Werder KV, Stevens WE, Cromwell TH, Eger EI, Forsham PH. Growth hormone secreton during long-term anesthesia in man. Horm Metab Res 1970; 2: 308-9.

13. Matsuki A, Sato K, Oyama T. Effects of muscle relaxant on adrenocortical function during halothane anesthesia in man. Agressologie 1971; 12: 149-55.
14. Oyama T, Maeda A, Kudo T. Effect of mild hypothermia and surgery on adrenocortical function in man. Agressologie 1971; 12: $217-22$.

15. Oyama T, Shibata S, Matsuki A, Kudo T. Thyroid-adrenocortical responses to anaesthesia in man. Anaesthesia 1969; 24: 19-27.

16. Oyama T, Aoki A, Kudo T. Effects of droperidol-pentazocine-N 2 $\mathrm{O}$ anaesthesia and surgery on human plasma testosterone levels. Anaesthesist 1972; 21: 364-5.

17. Oyama T, Takazawa T. Effects of halothane anaesthesia and surgery on human growth hormone and insulin levels in plasma. Br J Anaesth 1971; 43: 573-80.

18. Oyama T, Sato K, Kimura K. Plasma levels of antidiuretic hormone in man during halothane anaesthesia and surgery. Can Anaesth Soc J 1971; 18: 614-20.

19. Oyama T. Endocrine responses to anaesthetic agents. $\mathrm{Br} \mathrm{J}$ Anaesth 1973; 45: 276-81.

20. Oyama T. Effects of neuroleptanesthesia on endocrine function in man. Int Anesthesiol Clin 1973; 11: 171-84.

21. Oyama T. Anesthetic Management of Endocrine Disease. New York: Springer-Verlag; 1973. p. 235. 